\title{
Femtocell Performance Over Non-SLA xDSL Access Network
}

\author{
H. Hariyanto ${ }^{1}$, R. Wulansari ${ }^{1}$, Adit Kurniawan ${ }^{2}$ and Hendrawan ${ }^{2}$ \\ ${ }^{1}$ TELKOM RED Centre, Bandung \\ 2Bandung Instittue of Technology, Bandung \\ Indonesia
}

\section{Introduction}

Femtocells are low-power wireless access points; operate in licensed spectrum and use residential or office DSL, cable or other broadband connections. Most mobile network operators (MNOs) offer femtocell access point (FAP) to retain their customers by improving indoor coverage and capacity. However in order to leverage massive femtocells deployment and generate new revenue, there should be business cases beyond the connectivity. Offering various femto services are crucial to strengthen customer value preposition and create new revenue generator for operators. Each service certainly requires a specific amount of bandwidth and QoS treatment. Therefore the study of bandwidth and QoS requirement for different traffic types are important, in order to design an optimum backhaul requirement for femtocell.

Heavy Reading in its report [1] stated that the cost of leased line for macrocell backhaul counted $25 \%$ of total MNO's capex. The need of small cells are paramount important in delivering high speed wireless broadband data. However the cost of new carrier-grade backhaul to support indoor base stations (IBSs) may increase depend on the new IBSs numbers and availability of leased lines. Femtocells utilize the existing broadband connection in the customer side. By this approach, the cost of backhaul can be reduced with the trade off fluctuation on the backhaul quality; if there is no specific service level agreement (SLA) setup between MNO and internet service provider (ISP).

Bear in-mind that femtocell is a CPE with self configure capabilities, so that it will impose less interaction with mobile operators. For residential users, they may buy the femtocell from the mobile operator or electronic store and instantly plug it to the existing broadband connection at home. The users may not be aware of how the fixed-wireline operator will treat the femto traffic compared to other best-effort internet traffic. They may not be alert to that other broadband traffic traversed via the same home gateway will affect femtocell service performance. Bottleneck may occur anywhere in the network and affect femtocell performance.

A comprehensive femtocell deployment guideline considering backhaul quality for 3G femtocell was addressed in [2]. The guideline describes the quality issue of VoIP services over $3 \mathrm{G}$ femtocell networks. VoIP services were observed as representation of real time 
traffic. It was assumed that the users may complain to the cellular operator (instead of broadband IP provider) when they experience delay or poor Mean Opinion Score (MOS) during a voice call. As in 3G cases, users may wait for FTP data transfer or surfing the internet web site. In the latter case, higher latency or packet loss will not create a question from users than if the same situation experienced by users use VoIP or video services.

According to [2] and [3], most femtocell technologies provide good quality voice calls and sufficient support to data services when the broadband IP link provides a minimum performance of:

- Less than $150 \mathrm{~ms}$ round-trip delay (more than $200 \mathrm{~ms}$ will not be practical for two ways conversation);

- $\quad$ Less than 40 ms jitter;

- A general packet loss of $3 \%$ or less is acceptable; however, packet loss is typically "bursty" by nature, and, as such, average rates below $0.25 \%$ should be maintained;

- At least $1 \mathrm{Mbps}$ in downlink, i.e. from the broadband IP provider network to the FAP GW;

- $\quad$ At least $256 \mathrm{kbps}$ in uplink, i.e. from the FAP GW to the broadband IP provider network.

This chapter describes the femtocell performance over xDSL access network as the backhaul. This work has been conducted as part of TELKOM contribution to FREEDOM Project (www.ict-freedom.eu) which consists of two phases of measurements and analysis. The first phase addressed the performance of ADSL2, ADSL2+ as a function of distance. It also observes the population of user's density enjoying certain attainable rate or less. Furthermore it also addresses transmission delay of xDSL over different bandwidth profiles. DSL backhaul quality model is derived in order to address different qualities of backhaul. The model can be used in elaboration of RRM, scheduling and system level simulation which need to take into account the backhaul quality.

While in the first phase characterization, the measurement was conducted without femtocell, in the second phase we observed femtocell bandwidth requirement to support various basic services including HTTP, FTP, voice and video streaming. We limit the study for residential case where xDSL access network is used. In this case mobile network operator and $x$ DSL provider do not have agreement to maintain end-to-end QoS, hence non-SLA terminology is used. It should be understood that the bottleneck is not always occurred in the low speed backhaul, but it may occur event in high speed backhaul link; if the wireline broadband service requires a huge amount of bandwidth (for example high definition IPTV, video surveillance for home monitoring, etc).

The study of femtocell bandwidth requirement aims to observe the individual bandwidth consumption according to basic communication traffic types including HTTP, voice, video and FTP. For this purpose, we measured the bandwidth for 4-unit FAP and calculate bandwidth requirement for higher capacity FAP types such as 8-unit FAP which may be used in apartment deployment case. The bandwidth requirement study will give some insight to customer as well as operator, who deal with limited backhaul bandwidth, in order to understand how far their backhaul is capable of delivering basic communication services.

Based on the measurement result reported in FREEDOM, we will show the effect of background traffic in xDSL modem to the femtocell performance. Increasing the bandwidth 
may cope with the performance degradation but with the cost of adding more bandwidth to the existing broadband line. We also give some comments to the FREEDOM study outcome; how femtocell performance in non-SLA network can be improve by implementing backhaul aware scheduling and admission control [4].

\section{2. xDSL characterization}

xDSL technology offers fix broadband services over the existing copper twisted pair infrastructure. According to Organisation for Economic Co-operation and Development (OECD) as shown in Figure 1, the xDSL access technology has more subscribers compared to the other access technologies including fiber.

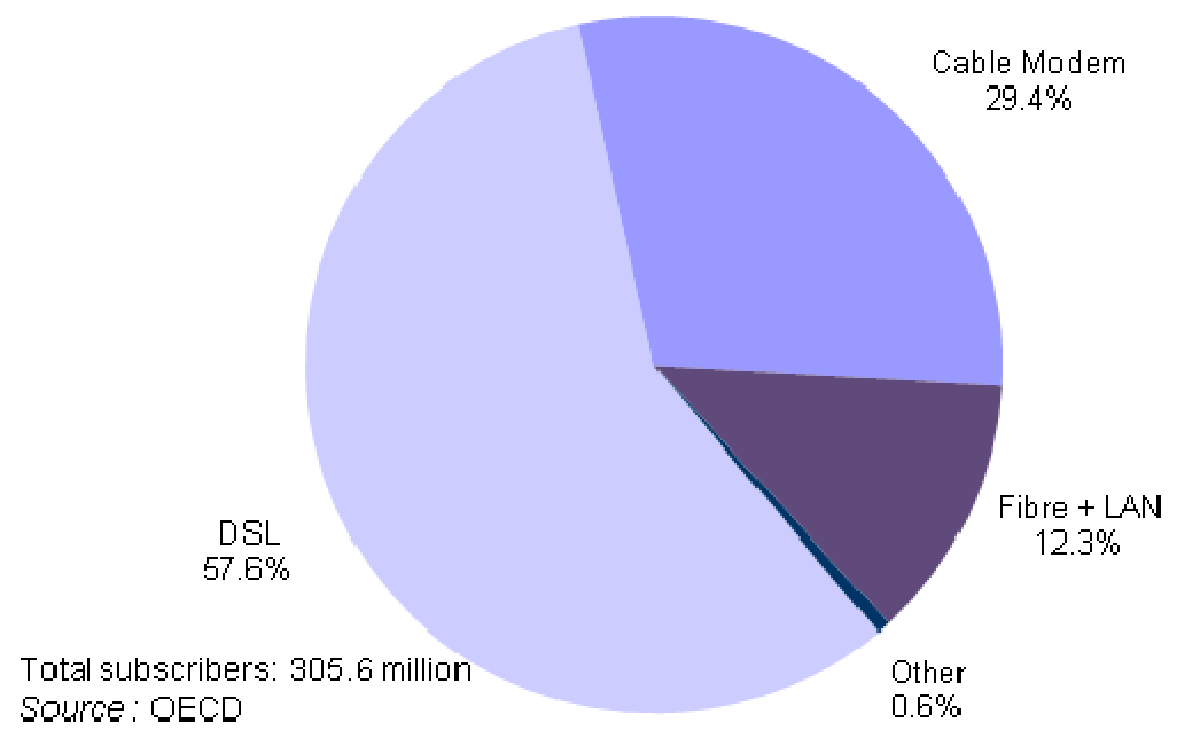

Fig. 1. OECD Fixed (wired) broadband subscriptions, by technology, Dec. 2010

The end user gets a dedicated link from xDSL modem to aggregation node called DSLAM (Digital Subscriber Line Access Multiplexer) or MSAN (Multi Switch Access network). There are several standards of xDSL which mostly asymmetric such as ADSL, ADSL2 and ADSL2+. The DSL also support symmetrical upstream and downstream ratio as in SDSL, SHDSL; however in terms of commercial penetration rate, asymmetrical DSL is higher compared to the symmetrical one, hence this paper pay more focus on asymmetrical DSL.

The ADSL2 standard, a recent version of ADSL, adopts enhanced modulation to reduce noise effect on the signals for higher coding gain and higher rate of the line. The ADSL2 system works at $50 \mathrm{~K}$ faster than the ADSL system and transmits signals $200 \mathrm{~m}$ farther, amounting to $6 \%$ more coverage. The newer version of ADSL is ADSL2. This standard issued in 2003 which referred to ITU-T G.992.5 standard. According to this standard, an ADSL2+ system shall work at up to $24 \mathrm{Mbps}$ or a higher rate on downstream with downstream frequency around 2.2 $\mathrm{MHz}$. 
ADSL and ADSL+ are deployed using the existing PSTN infrastructure. The DSLAM node is located in the central office and defined as aggregation nodes. The existing copper cable is used so that the broadband service can be evenly distributed from Local Exchange, Street Cabinet and household's area. The size of access network zone is determined by the maximum copper cable length [5]. At DSLAM side, traffic is multiplexed and transmitted over fiber based transmission to the IP backbone.

An ISP may implement xDSL technology using different approach including DSLAM in the local exchange (fiber to the exchange, FTTE), DSLAM/MSAN in the cabinet (fiber to the cabinet, FTTC) and DSLAM/MSAN in the building/house (fiber to the house/building, FTTH/FTTB). For this study, we focus on FTTE and FTTC deployment where MSANs are located in the central exchange (FTTE) and street cabinet respectively to reach customer residential with the cable length less than $4 \mathrm{~km}$.

\section{$2.1 \times D S L$ attainable rate}

The maximum attainable rate and allocated bandwidth per ISP plan (Mbps) will affect the femtocell performance. While the bandwidth allocation depends on subscription profile, maximum attainable rate are determined by corresponding xDSL technologies and physical copper cable quality (mainly characterized based on its attenuation and SNR).

In order to discuss about attainable rate and to derive xDSL quality model as femtocell backhaul, TELKOM conducted a study on its copper cable performance in supporting several xDSL technologies including ADSL2, ADSL2+, and VDSL2. Even though the study initially performed to assess IPTV implementation, the study result is relevant to support femtocell implementation.

The study of xDSL performance could not be separated by FTTx technologies implementation, since both are complementary to each other. Performance of transmission technologies over copper have been evaluated for the following reference architectures:

a. FTTE (DSLAM or MSAN in Exchange) which use technology: ADSL2/2+ technology as the last mile access

b. FTTC (MSAN in street cabinet) which uses technology: ADSL2/2+, VDSL2 (profile 8b, use the same Tx level as ADSL2/2+)

c. FTTB (ONU or MSAN at building) which uses technology: VDSL2 (profiles 17a and 30a)

The studies are performed by using simulation under Telecom Italy supervision. The cable models have been defined according to TELKOM's installed cables. Only FTTE and FTTC configuration will be described in this paper. While FTTE can provide internet service for subscriber located 3-5 away from Local Exchange, the FTTC can provide adequate and reasonable performance for residential in order to support IPTV service over xDSL broadband.

Structure of Telkom Indonesia cables can be summarized as following:

- Diameter of conductors: $0.6 \mathrm{~mm}-0.8 \mathrm{~mm}$

- Insulation: polyethylene

- $\quad$ Basic structure: quad (2 pairs) 
- First level of aggregation:

- $\quad$ For cables up to $100 \mathrm{cp}$ : Unit, consists of 5 quad (10 cp)

- $\quad$ For cables with $200 \mathrm{cp}$ or more: Super Unit of 25 quad (50 cp)

Based on those information, cable model were constructed based on the following parameter:

- Diameter of conductors: $0.6 \mathrm{~mm}$ (worst case)

- Attenuation: as of CT 1341 Italian cable, polyethylene insulated quad cable

- $\quad$ Reference cable binder:

- $\quad$ Primary cable: 50 pairs (1 super unit, 25 quads)

- $\quad$ Secondary cable: 50 pairs (5 units, $5 \times 5$ quads)

- Drop cable: 20 pairs

- Number of boxes per access binder: 3

- Number of drops per building cable: 4

Crosstalk model is based on following assumptions:

- NEXT reference value (@ $1 \mathrm{MHz}$ ) is considered the value @ $1 \%$ of the estimated statistical distribution

- $\quad$ FEXT reference value (@ $1 \mathrm{MHz}$ and $1 \mathrm{~km}$ ) is assumed as in standard (Recommendation ITU-T G996.1, ETSI 101 524)

- Crosstalk (statistical value @ 99\% of confidence):

- $\quad$ KNEXT (@ $1 \mathrm{MHz})=-52.2 \mathrm{~dB}$,

- $\quad$ KFEXT (@1 MHz@ $1 \mathrm{~km})=-45.0 \mathrm{~dB}$

Noise mix follows the assumption;

- $\quad$ Present broadband systems: 95\% ADSL2/2+ (over POTS), 5\% SHDSL, no regeneration allowed in access network

- Medium Term Broadband Services penetration assumed for performance estimation: $30 \%$

- Long Term Broadband Services penetration assumed for performance estimation: $50 \%$

- $\quad$ Noise mix composition for scenario (FTTC):

- $\quad$ Mix 30\%BB: 1 SHDSL (@2.3Mbit/s), 14 ADSL2/2+, 35 POTS (or vacant)

- Mix 50\%BB: 1 SHDSL (@2.3Mbit/s), 24 ADSL2/2+ or VDSL2, 25 POTS (or vacant)

xDSL Physical layer setting for performance evaluation follows

- $\quad$ Frequency Plan for VDSL2: $998 \mathrm{~Hz}$

- Physical layer setting for ADSL2/2+ ; Internet access services: NM=6dB, Channel Mode FAST ; IPTV services: NM=9dB, INP=2, Max Delay $=8 \mathrm{~ms}$

- Physical layer setting for VDSL2, IPTV services: $\mathrm{NM=9dB}$, INP=2, Max Delay=8ms

- ADSL2/2+ performance curves refer to systems implementing extended framing.

Based on the xDSL modeling, the simulation can provide the following results:

- $\quad$ ADSL2/ADSL2+ Performance in FTTE

- $\quad$ ADSL2/ADSL2+/VDSL2 Performance in FTTC

Based on above data and the xDSL modeling, the performance of ADSL2/ADSL2+ and VDSL2 can be seen in Figure 2 and Figure 3. 


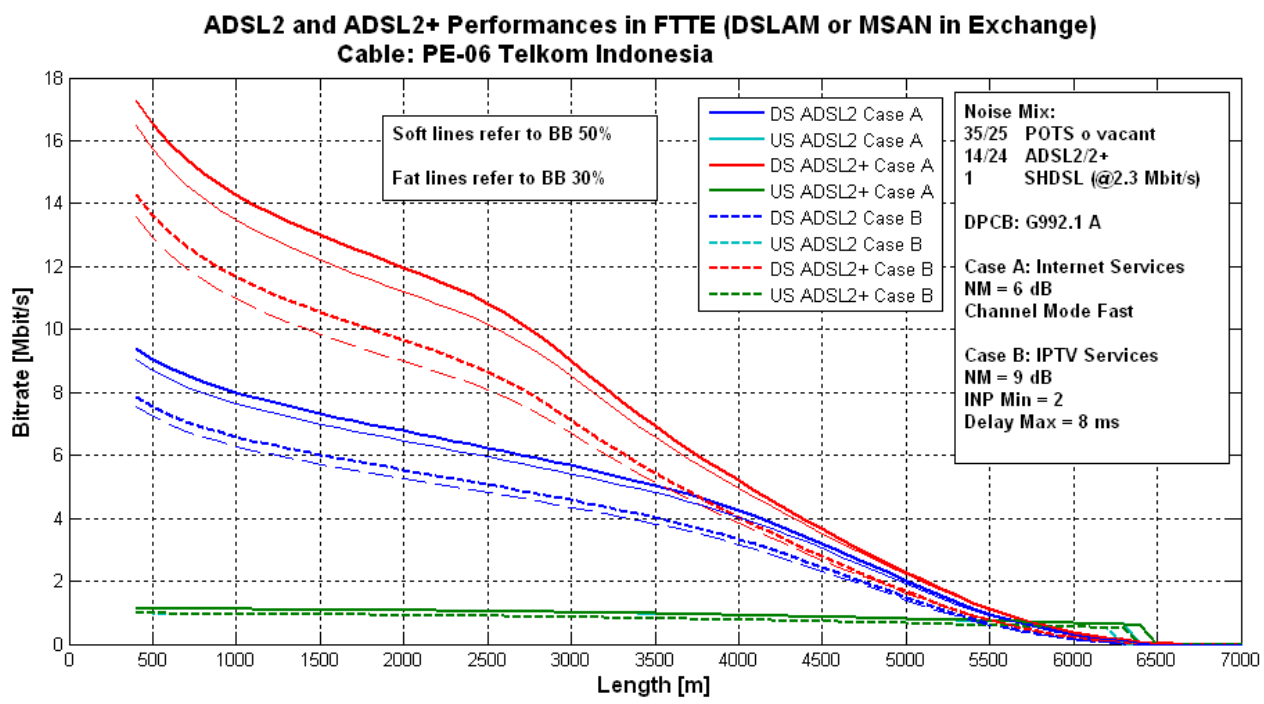

Fig. 2. Performance of ADSL2 and ADSL2+ using FTTE (MSAN at Local Exchange)

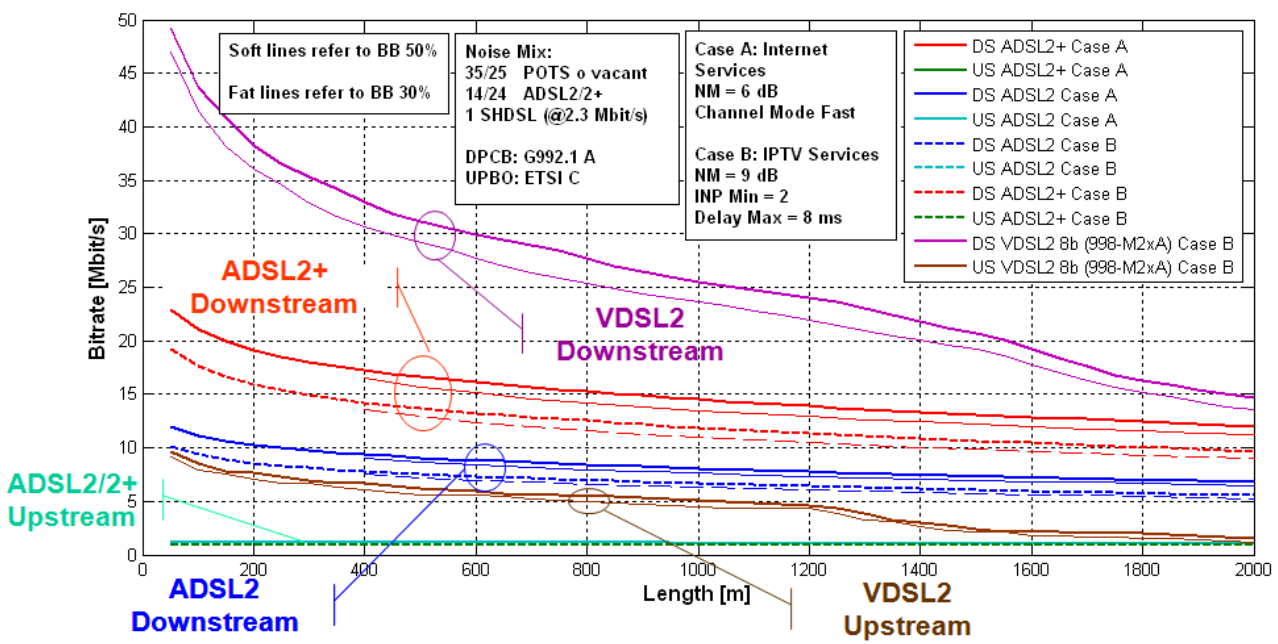

Fig. 3. Performance of ADSL2, ADSL2+ and VDSL in FTTC (MSAN at street cabinet)

In general, attainable data rate depend on xDSL technology. VDSL2 deliver higher data rate since it uses wider frequency plan up to $12 \mathrm{MHz}$ compared to ADSL2+ which uses $2.2 \mathrm{MHz}$ and ADSL2 uses $1.1 \mathrm{MHz}$. As the cable length increases the total impedance will also increase, it will add more attenuation to the signal. As a result the data rate will decrease as the cable length increase. Higher frequency will experience more sever attenuation as a function of distance, so that the higher data rate can only be maintained in shorter distance.

As can be seen from the graph, the maximum attainable rate also depends on xDSL channel mode. DSL is designed to deliver internet access. By default it uses fast channel 
mode, since it will offer a higher efficiency (more data, less error correction redundancy code in each packet). The fast channel mode will allow users to have faster and smaller ping times. However as the real time applications such as IPTV was introduced to the market, interleave channel mode is required. In video applications, there is no time to retransmit data if errors are detected. In order to limit the impact of long burst errors, an interleaver device is used to spread the data out or shuffles the data after encoded by the Reed-Solomon code [6]. By using Reed Solomon and interleaver as in ADSL and VDSL technology, long error bursts will be equally distributed, so that the errors can be corrected more easily using forward error correction. Since there are bits used for codeword, bits number for data in the interleave mode will be less, hence it will affect the total data rate.

ADSL2/ ADSL2+ has a limitation in the upstream bandwidth which is up to $1.1 \mathrm{Mbps}$, when FAST mode is used or up to $900 \mathrm{kbps}$ when INTERLEAVED is used. However this relatively high upstream bandwidth is only available if the cable length is less than 600 meter from MSAN location. To ensure the stability, $512 \mathrm{kbps}$ bandwidth should be considered for both modes, since the bandwidth is available even when the cable length $6 \mathrm{~km}$ away from MSAN location.

For higher upstream bandwidth, VDSL2 should be considered under FTTC configuration. With VDSL2, the upstream data rate can reach around $5 \mathrm{Mbps}$ at the range up to $1 \mathrm{Km}$.

\section{2 xDSL transmission delay}

In order to characterize $x$ DSL as femtocell backhaul, we also test transmission delay of ADSL and ADSL2+ from modem to the DSLAM. The experiment has been done in TELKOM R\&D Centre Test Bed (called OASIS). Due to the fact that the measurement conducted in the testbed, it is impossible to varying the cable length to have exact transmission delay observation. For the reason that delay is the inverse of frequency carrier, we measured the delay transmission by varying bandwidth profile. By limiting bandwidth profile, the frequency carrier is set and affects the transmission delay. We did not consider delay due to lost in cable as in the commercial DSL deployment.

The network configuration for this observation can be seen in Figure 4.

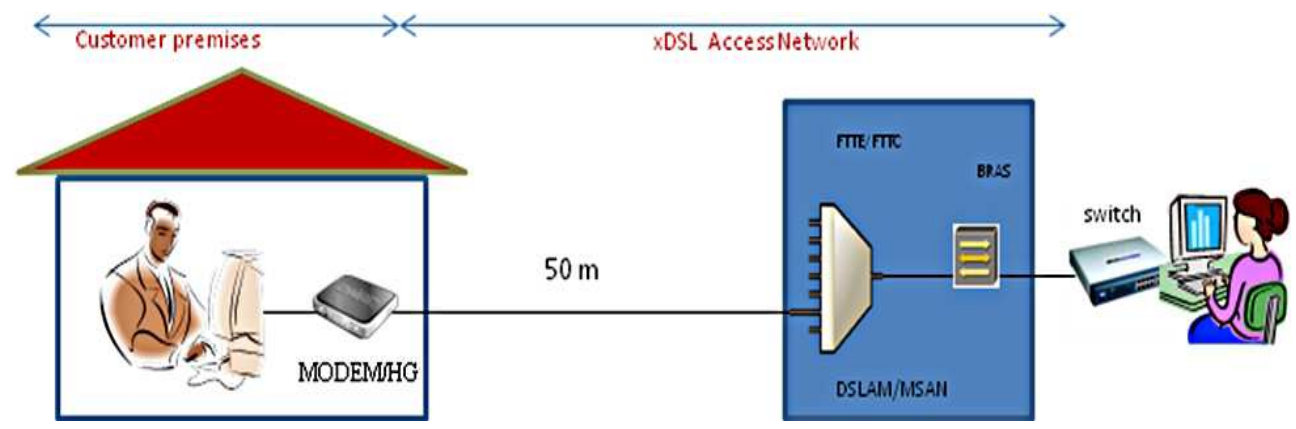

Fig. 4. Transmission Delay Measurement in TELKOM R\&D Centre's Testbed

The transmission delay of xDSL over various bandwidth profiles can be seen in Figure 5. 


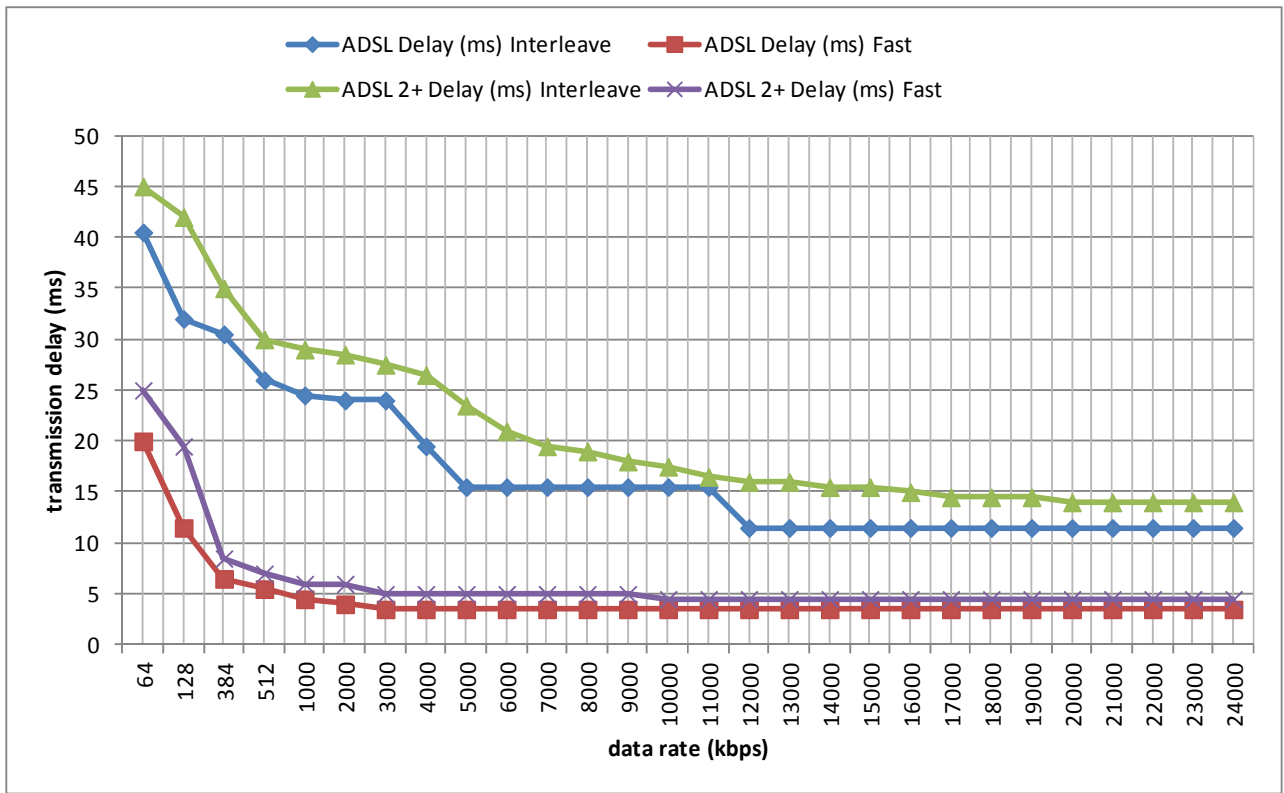

Fig. 5. Average delay transmission of ADSL/ADSL2+ over various bandwidth profile

It can be seen from the graph that the delay at $64 \mathrm{kbps}$ bandwidth is about $40 \mathrm{~ms}$ for fast mode and about two times for interleave. As the bandwidth increases the delay decreases since wider frequency bandwidth is required to produce more throughput.

\section{$2.3 \times$ XSL quality model}

We have discussed the maximum attainable rate which highly depends on DSL technologies, copper quality, relative distance from DSLAM/MSAN to the modem in user side and the channel modes implementation. However in the commercial point of view, the xDSL data rate is further limited by subscription profiles. An ISP usually offers various lines speed to the customer along with the broadband services. The penetration of fix broadband and line speed may vary from country to country depend on the penetration rate and the purchase power for individual line speeds.

We use Europe market as an example. According to Figure 6, as January 2010, there were about two-thirds of fixed broadband lines in the European region offered line speeds between 2 - $10 \mathrm{Mbps}$. While low speed broadband lines ranging from $144 \mathrm{kps}-2 \mathrm{Mbps}$ represent only $16 \%$ of all fixed broadband lines, the penetration of high speed broadband link above $10 \mathrm{Mbps}$ is about $23 \%$ of all fixed broadband. In terms of growth, most net fixed broadband additions in 2009 were for high speeds above 10+ Mbps. Most EU countries experienced a reduction in the proportion of low-speed fixed broadband lines.

Indonesia represents a development country. The growth rate of broadband Indonesia projected up to $49 \%$, but the penetration rate is estimated the lowest in Asia. In this broadband business the majority market $(67 \%)$ is served by TELKOM Group with its 


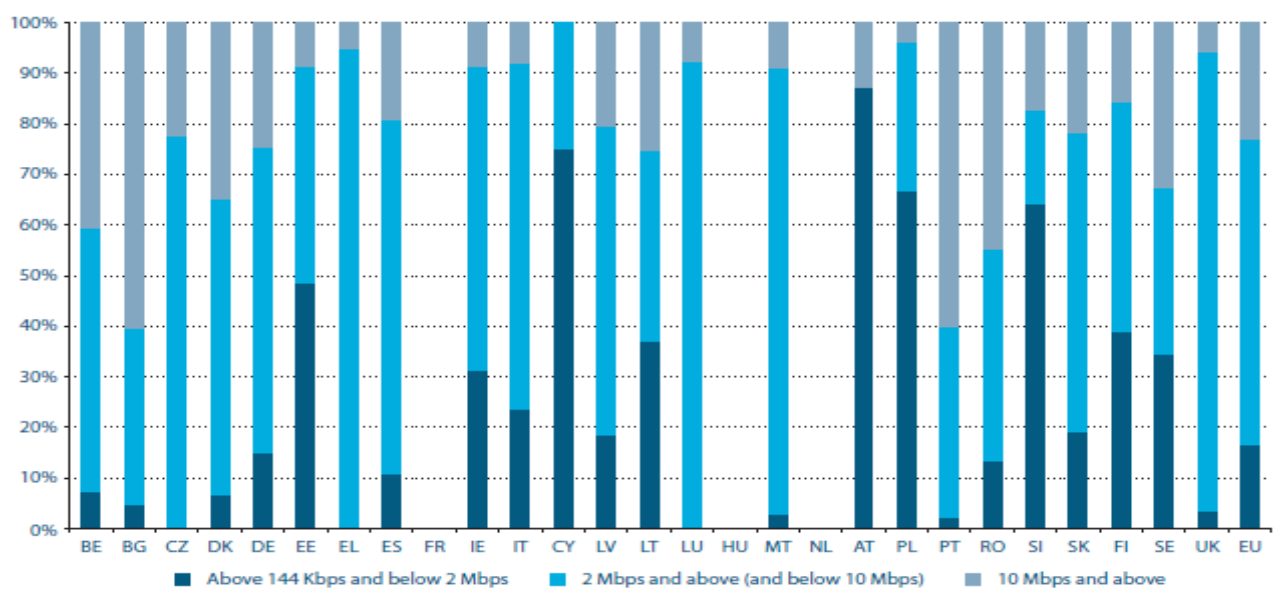

Fig. 6. Fixed Broadband Lines by Technology, January 2010 [7]

Telkom xDSL and Telkomsel mobile broadband. According to the market survey conducted in Jakarta 2011, the fixed broadband line subscription lower than 1 Mbps represent about $72.1 \%$ of population. The line speeds above $3 \mathrm{Mbps}$ represents $9.1 \%$ of population and the subscription of $2 \mathrm{Mbps}$ link is about $18.8 \%$.

By considering both technical characteristics and line speed penetration, we propose xDSL backhaul quality model for reference purpose for femtocell deployment. The model can be summarized in Table 1.

Low speed backhaul has relatively high penetration rate especially in Telkom Indonesia which is above $60 \%$. By using fast mode, it will allow to offer high speed internet access up to $4 \mathrm{Mbps}$. In terms of line speed, this type of backhaul can accommodate almost $100 \%$ subscribers with line speed below 3 Mbps. In European region, it will address only 16\% subscribers with line speed below 2 Mbps.

\begin{tabular}{|l|l|l|l|l|}
\hline \multicolumn{1}{|c|}{ Backhaul Types } & DL att. rate & UL att. Rate & $\begin{array}{c}\text { FTTx/DSL } \\
\text { Conf. }\end{array}$ & $\begin{array}{c}\text { Copper } \\
\text { Length }\end{array}$ \\
\hline Low Speed Backhaul & <2 Mbps & Up to $512 \mathrm{kbps}$ & $\begin{array}{c}\text { FTTE/FTTC with } \\
\text { ADSL2 / ADSL2+, fast } \\
\text { mode }\end{array}$ & $1-4 \mathrm{~km}$ \\
\hline $\begin{array}{l}\text { Medium Speed } \\
\text { Backhaul }\end{array}$ & 3-10 Mbps & Up to $1 \mathrm{Mbps}$ & $\begin{array}{c}\text { FTTC with ADSL2+, } \\
\text { fast and interleave } \\
\text { mode }\end{array}$ & $\leq 1 \mathrm{~km}$ \\
\hline High Speed Backhaul & 11-24 Mbps & $2-5 \mathrm{Mbps}$ & $\begin{array}{c}\text { FTTC with VDSL2, } \\
\text { fast and interleave } \\
\text { mode }\end{array}$ & $\leq 800 \mathrm{~m}$ \\
\hline
\end{tabular}

Table 1. xDSL Quality Model for Femtocell Deployment 
The medium bandwidth category (3 - $10 \mathrm{Mbps}$ in downstream direction) is usually used to accommodate IPTV, internet and hosted home video surveillance services. In the upstream direction, $1 \mathrm{Mbps}$ line speed can be considered when the copper length can be maintained less than 600 meter from MSAN location. By this medium speed backhaul, we assumed more than $50 \%$ DSL subscribers in most European region can have this line speed. While in Jakarta, IPTV service is still emerging, however in term of the attainable rate, it will potentially cover $30 \%$ DSL penetration and it will further increase as the deployment of FTTC is progressing.

Figure 7 illustrates the femtocell backhaul model based on the Table 1 . In distance $4 \mathrm{~km}$, backhaul quality will be limited. Theoritically ADSL2+ in $4 \mathrm{~km}$ can deliver $9 \mathrm{Mbps}$, however according to the real implementation it can only deliver 4-5 Mbps. By shortening the copper length using FTTC configuration where now copper length is maximum $1 \mathrm{~km}$, the backhaul quality is much better.

High speed backhaul (up to $24 \mathrm{Mbps}$ ) is offered to the customer who requires more bandwidth in both downstream and upstream direction. Currently this type of backhaul addresses more than $23 \%$ of all fixed broadband in most European Region. Even though VDSL2+ can offer more than $30 \mathrm{Mbps}$ data rate, the upstream data rate limits the overall performance. We limit the range of this backhaul type up to 800 meter distance in order to achieve 2-5 Mbps speed in the upstream.

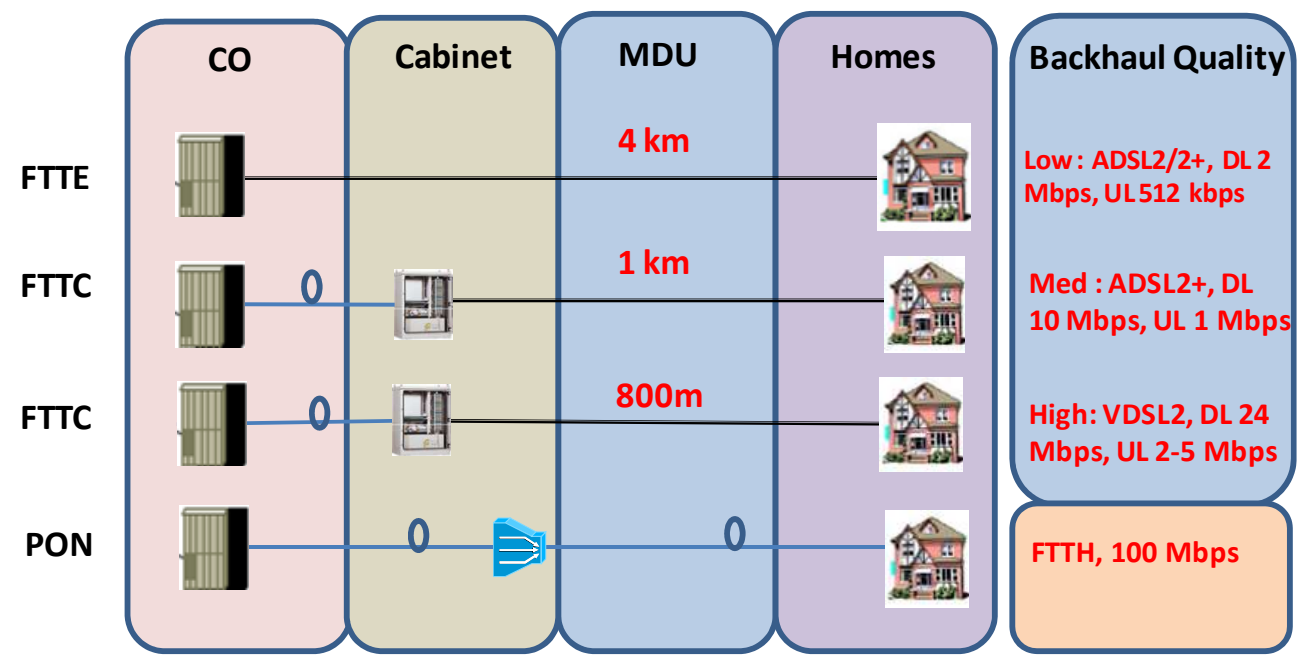

Fig. 7. Backhaul Quality Model

\section{Femtocell bandwidth requirement}

As been discussed in the previous section, femtocell utilizes the existing broadband IP access available in the customer home. As ADSL2/ADSL2+ has highest penetration rate compared to other fixed wireline access technologies, logically the initial femtocell deployment would have used this type of access. HSDPA Femtocell, for instance, has radio capacity about 7.2 Mbps downlink and 1.4 Mbps uplink. Low speed backhaul, as in Table 1, 
cannot completely accommodate the HDSPA full buffer in the air interface, so there may be bottleneck in the xDSL link. However if operator carefully analyze the individual bandwidth and QoS requirement for the basic communication services such as voice, http, ftp and video streaming, one can still hope that even low speed backhaul is able to support femtocell.

During connected mode, the bandwidth required by a FAP depends on service or application. Each service has its own traffic behavior. The aggregate traffic from different users will determine the total traffic occupied by the femtocell. However, in case Indonesian mobile operators, where the market is very competitive, $3 \mathrm{G}$ packet data offerings are based on unlimited data schemes. The offering may vary from $64 \mathrm{kbps}, 128 \mathrm{kbps}, 384 \mathrm{kbps}, 1.8 \mathrm{Mbps}$, 3.6 Mbps and 7.2 Mbps. The average bandwidth required by a FAP to support these offerings can be seen in Table 2 . The bandwidth is determined in the backhaul interface both for xDSL and Ethernet. As it can be seen from the table, that unlimited data packages of $64 \mathrm{kbps}, 128 \mathrm{kbps}$ from four different UEs can be supported by low speed backhaul category (below 2 Mbps downlink, 512 kbps uplink, according to xDSL case as in Table 1). Offers providing up to $384 \mathrm{kbps}, 1.8 \mathrm{Mbps}, 3.6 \mathrm{Mbps}$ and 7.2 Mbps should consider medium to high bandwidth quality. The constraint will be in uplink streams if the offering is symmetrical between uplink and downlink.

\begin{tabular}{|l|r|r|r|r|}
\hline \multicolumn{1}{|c|}{ Services } & \multicolumn{2}{|c|}{ xDSL } & \multicolumn{2}{c|}{ Ethernet } \\
\hline 12.2k CS voice & Downlink & Uplink & Downlink & Uplink \\
\hline 64k CS video & $84.8 \mathrm{kbps}$ & $84.8 \mathrm{kbps}$ & $62.4 \mathrm{kbps}$ & $62.4 \mathrm{kbps}$ \\
\hline 64k data & $212 \mathrm{kbps}$ & $212 \mathrm{kbps}$ & $163.2 \mathrm{kbps}$ & $163.2 \mathrm{kbps}$ \\
\hline 128k data & $83.9 \mathrm{kbps}$ & $83.9 \mathrm{kbps}$ & $74.5 \mathrm{kbps}$ & $74.5 \mathrm{kbps}$ \\
\hline 384k data & $167.7 \mathrm{kbps}$ & $167.7 \mathrm{kbps}$ & $149.1 \mathrm{kbps}$ & $149.1 \mathrm{kbps}$ \\
\hline HSDPA 1.8 & $503.2 \mathrm{kbps}$ & $503.2 \mathrm{kbps}$ & $447.3 \mathrm{kbps}$ & $447.3 \mathrm{kbps}$ \\
\hline HSDPA 3.6 & $2.3588 \mathrm{Mbps}$ & & $2.0967 \mathrm{Mbps}$ & \\
\hline HSDPA 7.2 & $4.7176 \mathrm{Mbps}$ & & $4.1934 \mathrm{Mbps}$ & \\
\hline HSUPA 1.4 & $9.4352 \mathrm{Mbps}$ & & $8.3868 \mathrm{Mbps}$ & \\
\hline
\end{tabular}

Table 2. Femtocell bandwidth estimation over xDSL and Ethernet

Those connectivity data offerings are indeed valid for macrocell. The MBS has been designed to anticipate peak data rate by utilizing carrier class backhaul. In case of femtocell, the backhaul is depending on broadband connectivity subscription in the customer side. The worse case situation is that, the backhaul bandwidth may be far below supported peak data rate of associate radio technology (HSPA, WiMAX, LTE, etc). Therefore we propose more realistic bandwidth requirement for a FAP by observing the individual bandwidth consumption of selected services. For this purpose, we measured the bandwidth for 4-unitcalls FAP (FAP which supports 4 simultaneous calls) which is commonly used for residential femtocell deployment. 


\subsection{Mesurement methodology}

Figure 8 shows xDSL and femto system installed in TELKOM RDC where ADSL2/ ADSL2+ is used. The DSLAM node connected to metro-ethernet located in TELKOM OASIS building located in Bandung. The SecGW and FAP GW are connected to metro-ethernet (ME) backbone to reach SGSN in 3G core network (through Iu-PS interface). Iu-CS connection (FAP GW to MSC in other city, 200km away from OASIS testbed) is also available for CS voice call. The connection between xDSL and Femto System and between Femto System and SGSN are considered as controlled environment. Since GGSN is a commercial network, the network load may affect the femtocell performance, especially during busy hours. Another drawback, it is impossible to put measurement tool (such as end-point) in the GGSN side limiting the impact to commercial network performance. For this reason, the measurement tool or application server as end point is put in the internet cloud. In positive way, the femtocell trial performed in this activity, will reflect the real condition.

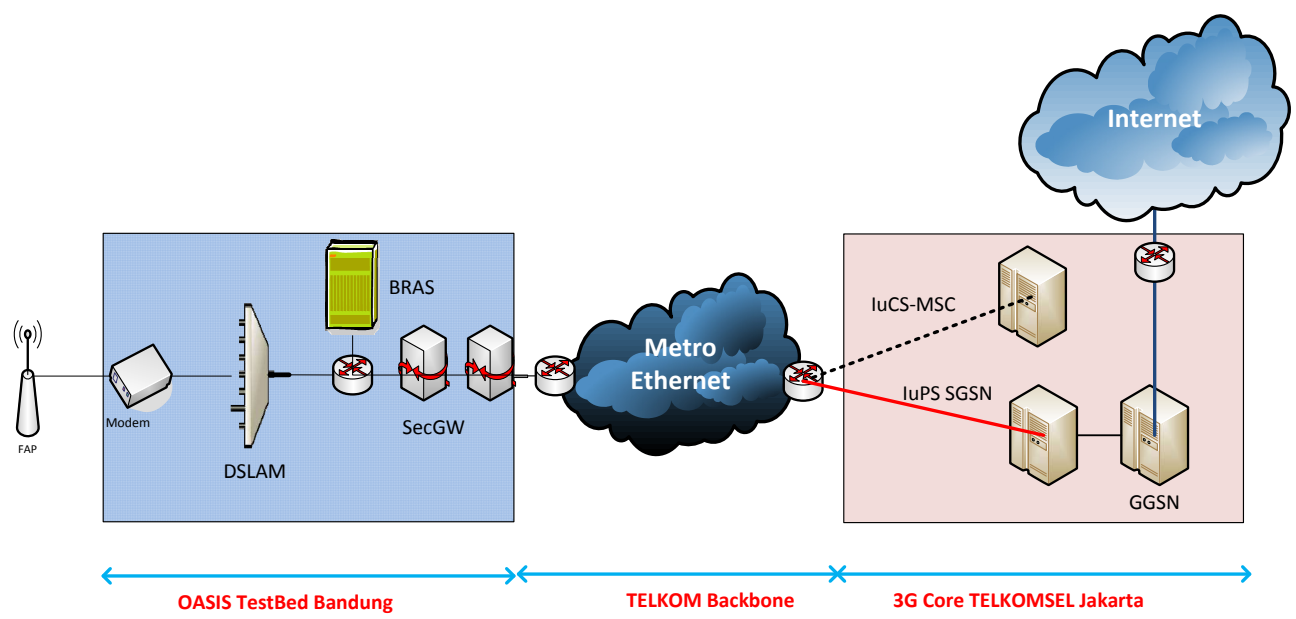

Fig. 8. xDSL as Femtocell Backhaul, A Reference Architecture

In order to derive bandwidth requirements (scenario 1) and femtocell performance (scenario 2), we define mix traffic composition which consists of HTTP, FTP, voice and video streaming. Individual content is defined according to the survey result conducted by TELKOM. There is several internet content accessed by subscribers of two major xDSL providers in Indonesia. As can be seen in Figure 9; facebook.com, detik.com, youtube.com, 4shared.com are among the most popular contents in Indonesia. Among top 10 internet content we choose detik.com or sometime facebook.com to represent HTTP traffic, youtube.com for streaming and 4 shared.com to download files from internet. Traffic mix definition being used in the measurement is written in Table 3.

In order to capture bandwidth required by a single FAP, 4 simultaneous UEs are setup to access the FAP. This scenario will be used as a basis to observe minimum xDSL bandwidth requirement and also as a reference of configuring traffic models in STC for observing femtocell performance. Since our focus on backhaul bandwidth, we limit the impact of radio channel fluctuation due to interference and mobility. In this case, FUEs will access the FAPs in such away; the FAPs's signal quality is very good and stable. 

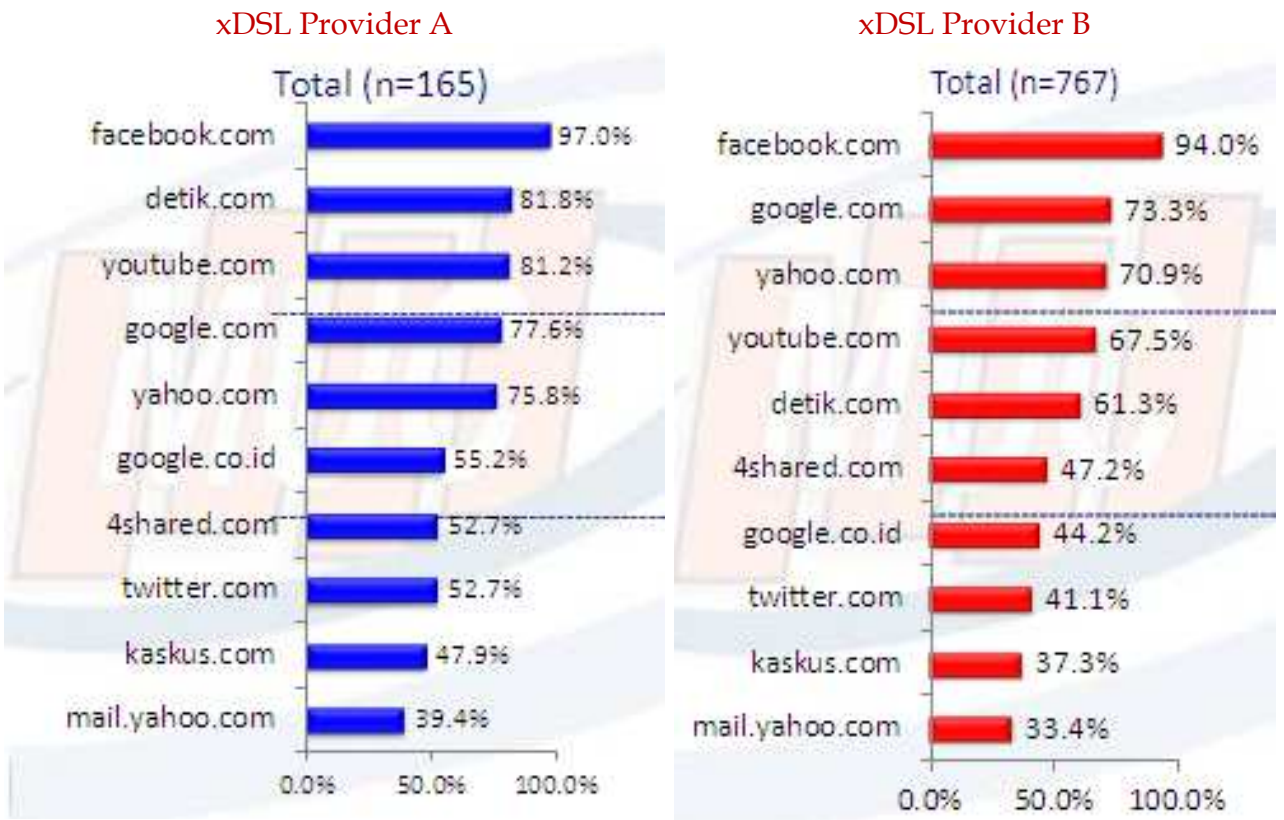

Fig. 9. Top 10 most visited internet content by subscriber of two ISPs in Indonesia

\begin{tabular}{|l|l|l|l|l|l|l|}
\hline Traffic Mix & \multicolumn{1}{|c|}{$\begin{array}{c}\text { Traffic } \\
\text { Source }\end{array}$} & \multicolumn{1}{|c|}{ HTTP } & File transfer & \multicolumn{1}{|c|}{$\begin{array}{l}\text { Video } \\
\text { streaming }\end{array}$} & Voice & \multicolumn{1}{|c|}{ Notes } \\
\hline $\begin{array}{l}\text { Smartphone } \\
\text { mix 4 CS Call }\end{array}$ & Real & - & - & - & AMR & scenario 1 \\
\hline $\begin{array}{l}\text { Smartphone } \\
\text { mix all traffic }\end{array}$ & Real & m.detik.com & $\begin{array}{l}4 \text { shared.com } \\
(5 \mathrm{MB})\end{array}$ & $\begin{array}{l}\text { youtube } \\
240 \times 360 \mathrm{p}\end{array}$ & AMR & scenario 1 \\
\hline $\begin{array}{l}\text { Tablet PC mix } \\
\text { all traffic }\end{array}$ & Real & $\begin{array}{l}\text { detik.com \& } \\
\text { facebook.com }\end{array}$ & $\begin{array}{l}4 \text { shared.com } \\
(13 \mathrm{MB})\end{array}$ & $\begin{array}{l}\text { youtube } \\
240 \times 360 \mathrm{p}\end{array}$ & - & $\begin{array}{l}\text { scenario } \\
1,2\end{array}$ \\
\hline $\begin{array}{l}\text { PC } \\
\text { Background }\end{array}$ & Real & Detik.com & FTP up to 40 MB & youtube & - & Scenario 2 \\
\hline Mix Traffic & $\begin{array}{l}\text { Generated and } \\
\text { Real }\end{array}$ & $\begin{array}{l}\text { detik.com \& } \\
\text { facebook.com }\end{array}$ & $\begin{array}{l}4 \text { shared.com } \\
(13 \mathrm{MB})\end{array}$ & $\begin{array}{l}\text { Video } \\
\text { conference }\end{array}$ & AMR & $\begin{array}{l}\text { scenario 1, } \\
2\end{array}$ \\
\hline
\end{tabular}

Table 3. Summary of traffic mix for femtocell performance using xDSL as the backhaul

The applications are accessed through various UE types including, smartphone and tablet PC. It is assumed that each user accesses only one service type. The traffic traversing through a FAP is recorded by Femto NMS. For this purpose, xDSL profile is set to maximum $(20 \mathrm{Mbps})$, so that the original bandwidth required to send traffic will go smoothly without any congestion or queuing in the access network. Since we use commercial GGSN, the traffic will be affected by the GGSN load, however we anticipated by using 3G SIM Card with the highest priority QoS profile defined in HLR/GGSN. Furthermore the individual test is 
repeated several times, i.e. 30 times effectively, but only the best 3 retries with similar statistical properties will be shown.

The measurement process was divided into two phases. Firstly, we captured individual bandwidth consumed by http, ftp, voice (AMR) and youtube streaming. The service was accessed from a smartphone connected to a FAP. Secondly, we observed the throughput for four simultaneous voice calls and mix traffic (HTTP, FTP, youtube, voice) from four different smartphone at the same time.

We repeated the similar observation for iPad. Since iPad is designed to access packet data only, hence voice AMR call cannot be tested. We replaced the voice call with facebook. We understood that most iPad users frequently download new applications, audio-video podcasts, mp3 music, ebooks from iTunes or Apple Store. For similarity with the observation in smartphone, we used ftp traffic from 4shared.com to download bigger file size compared to the one from smartphone. We also used the same page from detik.com. While from smartphone, mobile page version was displayed; in the iPad, full web page was displayed, hence the consumed bandwidth is different.

\subsection{Bandwidth requirement based on measurement result}

Bandwidth occupation by Mix traffic from smartphones and iPads can be seen in Figure 10 and Figure 11 respectively.

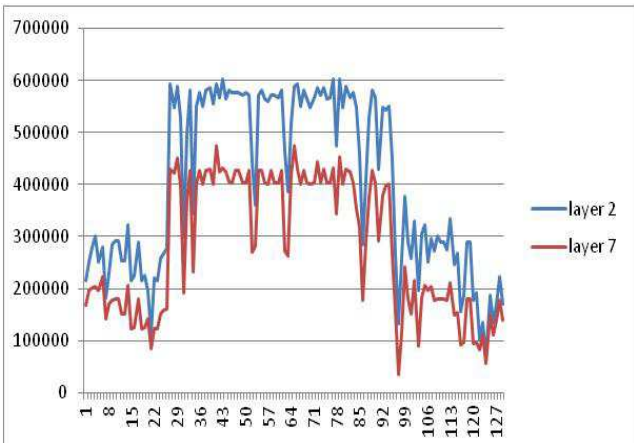

a) downlink

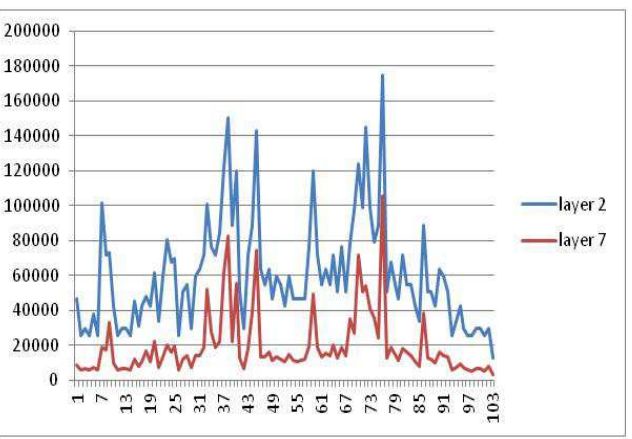

b) uplink

Fig. 10. Femtocell mix traffic bandwidth from 4 smartphones, measured in xDSL (layer 2) and application (layer 7)

The summary of statistical properties for individual traffic and mixed traffic accessed by both smartphone and iPad are shown in Table 4 and Table 5 respectively.

Since both DL and UL traffic follow lognormal distribution, maximum value is used so that all traffic can traverse smoothly. According to Table 4, we can see that the bandwidth required for a femtocell depends on the type of traffics. In downlink side it requires about $602 \mathrm{kbps}$ to perfectly handle mix traffic from 4 smartphones while in uplink is about 175 kbps. The uplink traffic in smartphone contains voice AMR (12.2kbps) so ideally the bandwidth should be preserved above $84.8 \mathrm{kbps}$. 


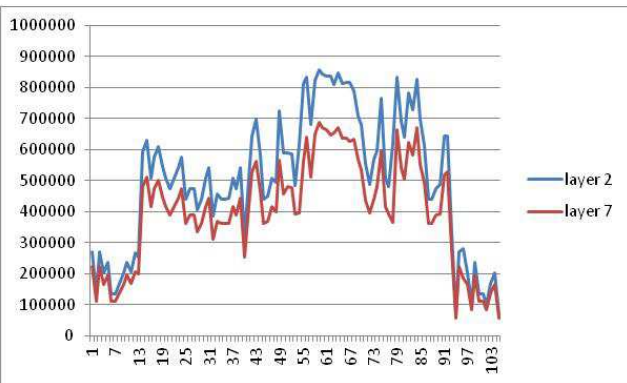

a) downlink

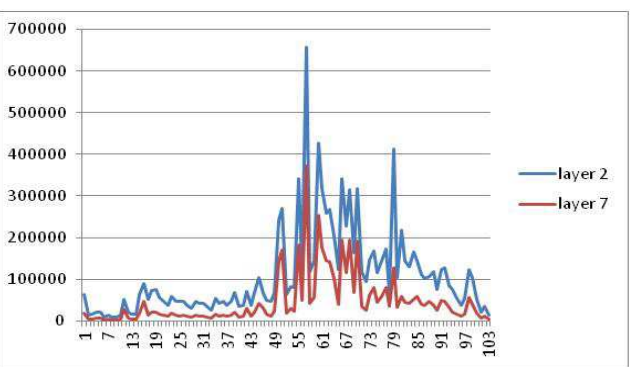

b) uplink

Fig. 11. Femocell mix traffic bandwidth from 4 iPads, measured in xDSL (layer 2) and application (layer 7)

In case of iPad being used as shown in Table 5, the downlink bandwidth consumption is about $857 \mathrm{kbps}$ and the uplink is about $632 \mathrm{kbps}$. The uplink traffic for iPad is higher than smartphone because mix traffic mainly used by youtube. However as can be seen from Figure 11 peak throughput of $632 \mathrm{kbps}$ is occurred only small portion compared to overall throughput shape, the rest of throughput is below $400 \mathrm{kbps}$.

\begin{tabular}{|c|c|c|c|c|c|c|c|}
\hline Traffic & Content & Strm & $\begin{array}{l}\text { Max } \\
\text { (bps) }\end{array}$ & $\begin{array}{l}\text { Min } \\
\text { (bps) }\end{array}$ & $\begin{array}{c}\text { Average } \\
\text { (bps) }\end{array}$ & Variance & Distribution \\
\hline \multirow[t]{2}{*}{ Cs voice } & \multirow[t]{2}{*}{ AMR 12,2 Kbps } & $\mathrm{DL}$ & 84,800 & 8,480 & $77,372.7$ & 466701399 & Lognormal \\
\hline & & UL & 84,800 & 8,480 & $77,372.7$ & 466701399 & Lognormal \\
\hline \multirow[t]{2}{*}{ HTTP } & \multirow{2}{*}{$\begin{array}{l}\text { m.detik.com, first } \\
\text { page }\end{array}$} & $\mathrm{DL}$ & 224,720 & 4,240 & $42,995.5$ & 3116322837 & Lognormal \\
\hline & & UL & 106,000 & 0 & $29,400.4$ & 886953056 & Lognormal \\
\hline \multirow[t]{2}{*}{ FTP } & \multirow{2}{*}{$\begin{array}{l}\text { www.4shared.com } \\
\text { "05.The Lazy Song”, } \\
\text { 5MB }\end{array}$} & $\mathrm{DL}$ & 576,640 & 4,240 & $185,196.8$ & 4640833694 & Normal \\
\hline & & UL & 42,400 & 0 & $16,178.7$ & 43352265 & Lognormal \\
\hline \multirow[t]{2}{*}{ Streaming } & \multirow{2}{*}{$\begin{array}{l}\text { m.youtube.com, "If } \\
\text { you sleep in at my } \\
\text { house, you are } \\
\text { "Doom"ed", 41s, 240p, } \\
380 \text { Kbps }\end{array}$} & $\mathrm{DL}$ & 339,200 & 29,680 & $278,521.7$ & 7042225332 & Normal \\
\hline & & UL & 71,016 & 8,480 & $27,326.68$ & 148142570 & Lognormal \\
\hline \multirow[t]{2}{*}{ Mix } & \multirow[t]{2}{*}{4 CS call } & $\mathrm{DL}$ & 339,200 & 8,480 & $298,168.5$ & 8044648128 & Lognormal \\
\hline & & UL & 339,200 & 8,480 & $298,168.5$ & 8044648128 & Lognormal \\
\hline \multirow[t]{2}{*}{ Mix } & \multirow[t]{2}{*}{ All traffic } & $\mathrm{DL}$ & 602,080 & 67,840 & $400,326.4$ & 19280386460 & Lognormal \\
\hline & & UL & 174,896 & 12,720 & $60,522.33$ & 768972191 & Lognormal \\
\hline
\end{tabular}

Table 4. Statistical properties of individual and mix traffic in smartphone case

So far we have derived the bandwidth requirement for femtocell by monitoring the throughput from Femtocell NMS.

- $\quad$ BR for smartphone $=607 \mathrm{kbps}(\mathrm{DL})$ and $175 \mathrm{kbps}(\mathrm{UL})$

- $\quad$ BR for iPad $=857 \mathrm{kbps}$ (DL) and $400 \mathrm{kbps}$ (UL) 


\begin{tabular}{|c|c|c|c|c|c|c|c|}
\hline Traffic & Content & Strm & $\begin{array}{l}\text { Max } \\
\text { (bps) }\end{array}$ & $\begin{array}{l}\text { Min } \\
\text { (bps) }\end{array}$ & $\begin{array}{c}\text { Average } \\
\text { (bps) }\end{array}$ & Variance & Distribution \\
\hline \multirow[t]{2}{*}{ HTTP } & \multirow{2}{*}{$\begin{array}{l}\text { www.detik.com, first } \\
\text { page }\end{array}$} & DL & $1,094,976$ & 12,720 & $282,005.8$ & $2,24269 \mathrm{E}+11$ & Normal \\
\hline & & UL & 168,536 & 0 & $94,768.0$ & 2549473195 & Normal \\
\hline \multirow[t]{2}{*}{ HTTP } & \multirow{2}{*}{$\begin{array}{l}\text { www.facebook.com, } \\
\text { home page }\end{array}$} & $\mathrm{DL}$ & 561,800 & 0 & $109,618.1$ & 18271227072 & Lognormal \\
\hline & & UL & 210,936 & 0 & $45,605.9$ & 3675590487 & Lognormal \\
\hline \multirow[t]{2}{*}{ FTP } & \multirow{2}{*}{$\begin{array}{l}\text { www.4shared.com } \\
\text { "divxim.net-kLite } \\
\text { Codec Pack 4.9.5 } \\
\text { FULL", 13,6MB }\end{array}$} & DL & 407,040 & 4,240 & $213,622.6$ & 3926226329 & Normal \\
\hline & & UL & 59,360 & 0 & $22,047.5$ & 65333480 & Lognormal \\
\hline \multirow[t]{2}{*}{ Streaming } & \multirow{2}{*}{$\begin{array}{l}\text { m.youtube.com, "If } \\
\text { you sleep in at my } \\
\text { house, you are } \\
\text { "Doom"ed", 41s, 240p, } \\
380 \text { Kbps }\end{array}$} & DL & 339,200 & 4,240 & $280,032.6$ & 4284588520 & Normal \\
\hline & & $\mathrm{UL}$ & 48,760 & 12,720 & $27,491.1$ & 61155798 & Lognormal \\
\hline \multirow[t]{2}{*}{ Mix } & \multirow[t]{2}{*}{ All traffic } & DL & 857,536 & 67,840 & 501,702 & 10293926961 & Normal \\
\hline & & UL & 658,256 & 8,480 & $106,523,7$ & 13009342028 & Lognormal \\
\hline
\end{tabular}

Table 5. Statistical properties of individual and mix traffic in iPad case

\section{Femtocell performance}

In this section, the performance of a femtocell service is observed in the presence of background traffic in xDSL modem. This observation will effectively address the nature of FAP which is customer premises equipment. It is most likely that the user will plug the FAP to $x$ DSL modem or home gateway on top of the existing broadband access in the home. Without prior notice, the femtocell service will be mixed with traffic from PC or other devices connected to the same modem.

\subsection{Measurement methodology}

Scenario 2 was defined to verify femtocell performance in the existence of background traffic in xDSL modem. This scenario is designed to show that if MNO and xDSL provider does not sign an agreement, the internet traffic and FAP traffic will be mixed into a single PVC (Physical Virtual Connection), so that regardless the QoS setting in the modem, both traffic will have a same priority and compete each other as best effort.

The femtocell and PC are connected to xDSL modem using single PVC (Physical Virtual Connection) so that the traffic will mix each other. We set the DSLAM to interleave mode, while the modem uses default UBR (Universal Bit Rate) type of service. The PC generated mixed traffic HTTP (www.detik.com), FTP (rapidshared $40 \mathrm{Mbps}$ ) and youtube. The background will use real DSL traffic generated from the measurement tools. We use the same network reference architecture as in Figure 8, except that in the modem/home gateway there is a PC and a femtocell connected to the modem. The PC generates traffic mix (called PC background) as defined in Table 3.

Femtocell is attached to serve 4 FUEs simultaneously. We are referring to iPad case to inline with the maximum BR obtained from previous observation. By using iPad case which has 
higher bandwidth consumption, the bandwidth requires for smartphone case logically will also be supported. For femtocell we use generated traffix mix from Spirent Test Centre (STC) and Cisco Telepresence Service. This is important since we need a reference service performance to be monitored in the presence of other traffic from other FUEs as well as the PC. In this case video conference is used since it has several performance metrics including throughput, jitter and packet loss for both video and audio quality. In order to approach femtocell BR obtained from bandwidth requirement observation which uses real traffic, we generated mix traffic from STC is made as close as possible to the iPad mix traffic. The comparison between generated traffic and real iPad mixed traffic can be seen in Figure 12.

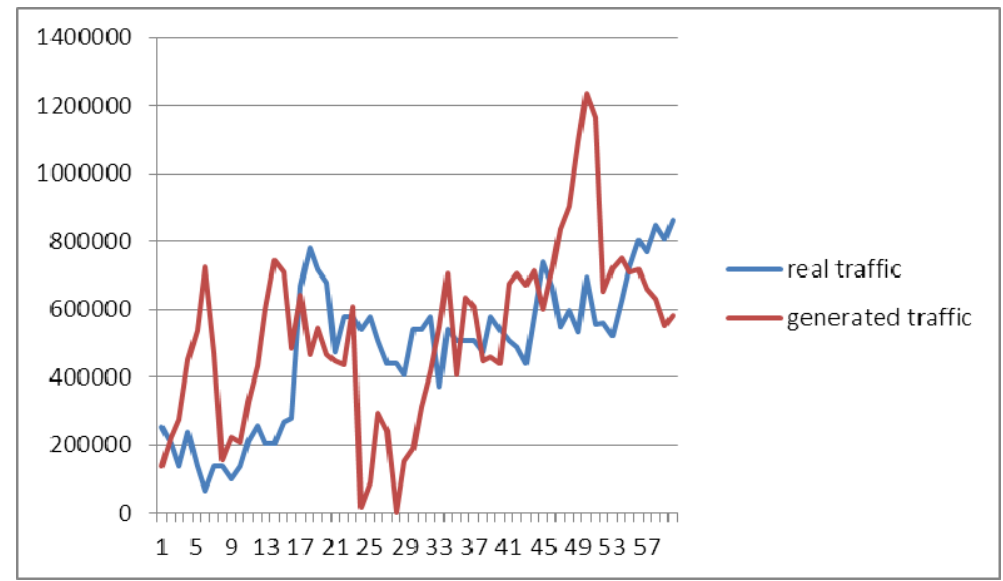

Fig. 12. The comparison between generated traffic and iPad mix traffic

The test scenario is divided into two sub scenarios. The first sub-scenario is to obtain the femtocell performance without background traffic. While in the bandwidth requirement measurement (scenario 1) we set xDSL profile only to $20 \mathrm{Mbps}$; in this sub-scenario we set the line bandwidth to $20 \mathrm{Mbps}, 1 \mathrm{Mbps}$, and $800 \mathrm{kbps}$. In each line profile we observed the video-audio performance. It will give a performance reference as well as verification to the BR obtained from scenario 1 .

In the second sub-scenario we activate the traffic from PC. We then analized the performance of video conference (packet loss, jitter) with the existence of background traffic. In this case we used reference performance of xDSL set to $1 \mathrm{Mbps}$ without background and compare the new video performance in the presence of background from PC. We increased the bandwidth profile step by step until the video performance below the threshold (packet loss $<3 \%$, jitter $<40 \mathrm{~ms}$ ).

\subsection{Performance degradation due to background traffic in access}

Table 6 shows the video conference performance without PC background. When the xDSL bandwidth profile set to $800 \mathrm{Kbps}$ or equal to BR for iPad, the video quality for iPad is maintained below the threshold; the packet loss below 3\% and the jitter far below than $40 \mathrm{~ms}$. By giving $20 \%$ more bandwidth to $1 \mathrm{Mbps}$ it will give additional space to anticipate other header and load during busy hours and also it will give better performance for real time 
traffic. In this case, it gives less jitter and increase throughput. TELKOM usually adds $20 \%$ on top of bandwidth requirement to engineer xDSl line speed, hence $1 \mathrm{Mbps}$ line speed is used. It can be shown from Table 6 that the performance metrics of $1 \mathrm{Mbps}$ line is closed to $20 \mathrm{Mbps}$.

\begin{tabular}{|c|c|c|c|c|c|c|}
\hline \multirow{2}{*}{ Mode } & \multicolumn{6}{|c|}{ Average Video Quality for 5 minutes observation } \\
\cline { 2 - 7 } & \multicolumn{2}{|c|}{ Bitrate (kbps) } & \multicolumn{2}{c|}{ Packet loss (\%) } & \multicolumn{2}{c|}{ Jitter (ms) } \\
\cline { 2 - 7 } & $\mathbf{T x}$ & $\mathbf{R x}$ & $\mathbf{T x}$ & $\mathbf{R x}$ & $\mathbf{T x}$ & $\mathbf{R x}$ \\
\hline $20 \mathrm{Mbps}$ & 83.58 & 23.53 & 0.53 & 2.45 & 13.30 & 19.53 \\
\hline $1 \mathrm{Mbps}$ & 78.93 & 22.93 & 0.34 & 2.47 & 12.23 & 20.75 \\
\hline $800 \mathrm{Kbps}$ & 84.70 & 20.26 & 0.37 & 2.12 & 13.45 & 24.96 \\
\hline \multirow{3}{*}{ Mode } & \multicolumn{6}{|c|}{ Average Audio Quality for 5 minutes observation } \\
\cline { 2 - 7 } & \multicolumn{2}{|c|}{ Bitrate (kbps) } & \multicolumn{2}{c|}{ Packet loss (\%) } & \multicolumn{2}{c|}{ Jitter (ms) } \\
\cline { 2 - 7 } & Transmit & Receive & Transmit & Receive & Transmit & Receive \\
\hline $20 \mathrm{Mbps}$ & 49.33 & 25.38 & 0.14 & 0.47 & 7.38 & 3,3 \\
\hline $1 \mathrm{Mbps}$ & 49.33 & 25.38 & 0.14 & 0.47 & 7.38 & 3,3 \\
\hline $800 \mathrm{Kbps}$ & 54.81 & 27.21 & 0.16 & 1.25 & 6.68 & 9.9 \\
\hline
\end{tabular}

Table 6. H264 Video Conference Performance without PC background

We use video conference as reference in order to see the effect of background traffic from PC to the femto service performance, in this case video conferencing. It can be seen from Table 7, as

\begin{tabular}{|c|c|c|c|c|c|c|}
\hline \multirow{3}{*}{ Mode } & \multicolumn{6}{|c|}{ Average Video Quality } \\
\hline & \multicolumn{2}{|c|}{ Bitrate (kbps) } & \multicolumn{2}{|c|}{ Packet loss (\%) } & \multicolumn{2}{|c|}{ Jitter (ms) } \\
\hline & $T x$ & $R x$ & $T x$ & $\mathrm{Rx}$ & $T x$ & $\mathbf{R x}$ \\
\hline $20 \mathrm{Mbps}$ & 81.83 & 24.97 & 1.25 & 2.47 & 13.92 & 18.05 \\
\hline 2 Mbps & 84.25 & 23.73 & 0.29 & 2.99 & 13.62 & 35.22 \\
\hline $1,5 \mathrm{Mbps}$ & 85.28 & 26.48 & 0.38 & 4.43 & 15.70 & 29.95 \\
\hline 1,2 Mbps & 82.26 & 23.19 & 0.33 & 5.94 & 14.64 & 41.11 \\
\hline $1 \mathrm{Mbps}$ & 89.07 & 27.85 & 0.12 & 3.96 & 13.87 & 45.52 \\
\hline \multirow{3}{*}{ Mode } & \multicolumn{6}{|c|}{ Average Audio Quality } \\
\hline & \multicolumn{2}{|c|}{ Bitrate (kbps) } & \multicolumn{2}{|c|}{ Packet loss (\%) } & \multicolumn{2}{|c|}{ Jitter (ms) } \\
\hline & Transmit & Receive & Transmit & Receive & Transmit & Receive \\
\hline $20 \mathrm{Mbps}$ & 56.67 & 58.92 & 0.82 & 0.66 & 7.02 & 3.95 \\
\hline $2 \mathrm{Mbps}$ & 52.00 & 25.33 & 0.18 & 0.95 & 7.35 & 14.08 \\
\hline 1,5 Mbps & 27.43 & 25.02 & 0.07 & 1.22 & 8.45 & 16.88 \\
\hline 1,2 Mbps & 47.08 & 26.92 & 0.13 & 1.67 & 7.00 & 16.85 \\
\hline $1 \mathrm{Mbps}$ & 28.57 & 25.45 & 0.05 & 1.32 & 10.20 & 17.57 \\
\hline
\end{tabular}

Table 7. H264 Video Conference Performance in the presence of background traffic from PC

soon the background traffic exist, the packet loss of video quality increase from $2.47 \%$ to $3.98 \%$ and the jitter double from $20.75 \mathrm{~ms}$ to $45.52 \mathrm{~ms}$. In order to improve the video performance we increase the xDSL bandwidth profile from $1 \mathrm{Mbps}$ to $1.2 \mathrm{Mbps}$, $1.5 \mathrm{Mbps}$ and $2 \mathrm{Mbps}$. When it set to $2 \mathrm{Mbps}$, the packet loss is below 3\%, and the jitter is also below 
40 ms. In this case, when the femto and PC using the same PVC, ones can improve the performance of femtocell by subscribing more xDSL bandwidth about double than the required bandwidth by a FAP. Of course the final bandwidth is sensitive to the amount of internet traffic from local area network (PCs).

Figure 13 shows the mix traffic from femtocell and PC when BW profile set to $20 \mathrm{Mbps}$. Even though the average total traffic from both femtocell and PC is about $2.2 \mathrm{Mbps}$, setting up line speed to $2 \mathrm{Mbps}$ has given acceptable performance to the real time femtocell traffic.

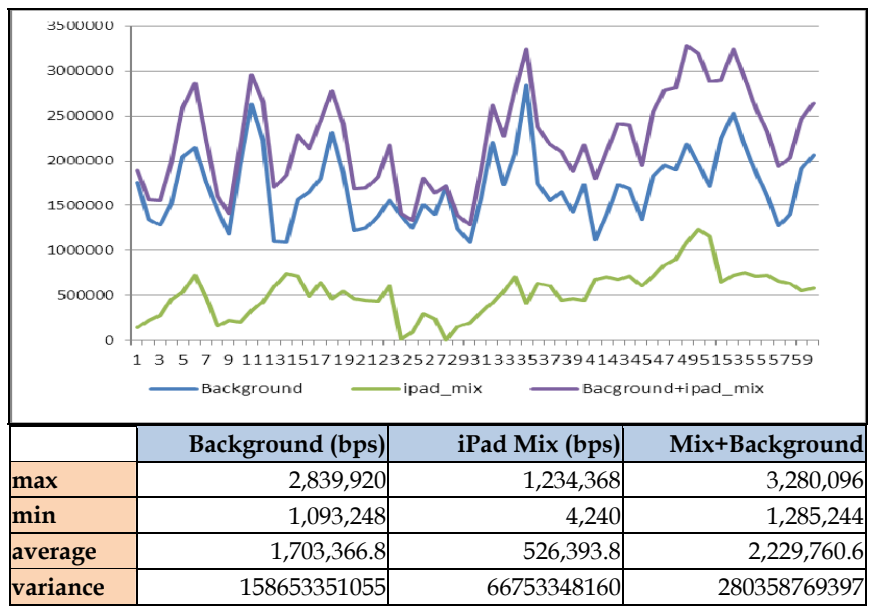

Fig. 13. Aggregate Throughput in xDSL link, BW profile set to $20 \mathrm{Mbps}$

\section{Conclusion}

In this chapter the xDSL characteristics has been explained including xDSL attainable rate and transmission delay. Based on TELKOM study result, the performance of ADSL2, ADSL2+ and VDSL2 under FTTE, FTTC and FTTB configuration have been discussed. The backhaul quality model for $\mathrm{xDSL}$ has been proposed in order to accommodate both technical limitation of $\mathrm{xDSL}$ (in example cable length and constaint in xDSL uplink bandwidth) and current penetration rate of bandwidth subscription profiles both in Indonesia and Europe. DSL backhaul quality model is derived in order to address different qualities of backhaul. The model has been used in FREEDOM project in elaboration of cooperative RRM, scheduling and system level simulation which need to take into account the backhaul quality.

According to the performance measurement result, it can be concluded that the femtocell performance can be affected by internet traffic in the xDSL modem. This case mostly happens when the users instantly plug in the femtocell to their broadband connection without knowing that the traffic from a FAP and PC could compete to each other without any priority or separation. This is also true if the xDSL service provider is a separate company, and there is no service level agreement with the femtocell service provider in order to maintain end-to-end QoS.

In order to achieve better performance for femtocell, the customer should have additional bandwidth to accommodate both traffic. Alternatively an integrated modem-femtocell 
solution (home-gateway with femtocell capability) can be introduced in order to have jointscheduling between xDSL modem and femtocell.

Implementing backhaul aware scheduling (BAS) in the femtocell can be another alternative in order to minimize the impact of bottleneck in the backhaul to the femtocell service performance [4]. This study was driven by the limitation of backhaul capacity (e.g., bottleneck or congestion) caused by other traffic (e.g., IPTV or Internet access in XDSL modem) which affects the performance of FAP in serving requested traffic from femtocell users. The admission control is incorporated with the scheduling method to treat all kinds of traffic served by the FAP. With BAS, the FAP can decide whether the backhaul capacity is enough or not to support existing session. The simulation results show that with BAS, the performance of FAP can be improved especially for peak backhaul conditions compared to FAP without BAS.

\section{Acknowledgment}

This work has been performed in the framework of the FP7 project FREEDOM IST-248891 STP, which is partially funded by the European Community. The Authors would like to acknowledge the contributions of colleagues from FREEDOM Consortium [8], TELKOMSEL, HUAWEI and CISCO who supported the measurement campaign and gave technical assistant.

\section{References}

[1] Patrick Donegan, "Backhaul Strategies for Mobile Carriers", Heavy Reading Report Vol. 4, No. 4, March 2006

[2] Epitiro Technologies, Ltd, Femtocell Deployment Guide: An Operator-focused Strategy for a Successful Femtocell Rollout, 2008

[3] Simon R. Saunders, Stuart Carlaw, Andrea Giustina, Ravi Raj Bhat, V. Srinivasa Rao and Rasa Siegberg."Femtocell Opportunities and Challenges for Business and Technology", 2009 John Wiley \& Sons Ltd.

[4] Hariyanto, Hadi; Noviyanti, Karina W.; Widiawan, A K.; Kurniawan, Adit; Hendrawan; "Backhaul-aware scheduling for WiMAX femtocell with limited backhaul capacity", TENCON 2011 - 2011 IEEE Region 10 Conference, Digital Object Identifier: 10.1109/TENCON.2011.6129013, Page(s): 1280 - 1284, 2011.

[5] H. M. Sigurdsson,K. E. Skouby, "Techno-economic evaluation of broadband access technologies: The BREAD approach", Center for Information and Communication Technologies, CICT Technical University of Denmark

[6] P. Golden, H. Dedieu, K. Jacobsen, "Fundamental of xDSL Technologies", Auerbach Publications, Taylor \& Francis Group, New York, 2006.

[7] European Commission, "Europe's Digital Competitiveness Report", Publication Office of the European Union, Luxembourg, 2010

[8] FP7-ICT-2009-4, FREEDOM "Femtocell-based netwoRk Enhancement by intErference management and coorDination of infOrmation for seaMless connectivity", http://www.ict-freedom.eu/. 


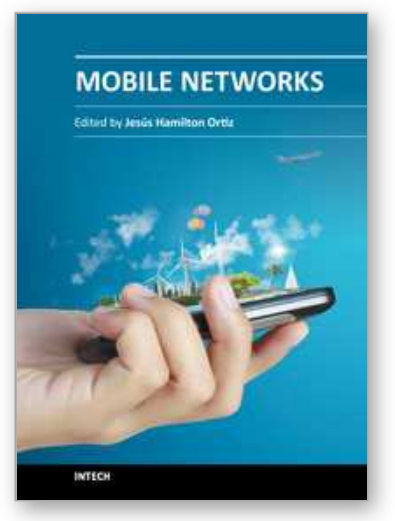

\author{
Mobile Networks \\ Edited by Dr. Jesús Ortiz
}

ISBN 978-953-51-0593-0

Hard cover, 192 pages

Publisher InTech

Published online 09, May, 2012

Published in print edition May, 2012

The growth in the use of mobile networks has come mainly with the third generation systems and voice traffic. With the current third generation and the arrival of the $4 \mathrm{G}$, the number of mobile users in the world will exceed the number of landlines users. Audio and video streaming have had a significant increase, parallel to the requirements of bandwidth and quality of service demanded by those applications. Mobile networks require that the applications and protocols that have worked successfully in fixed networks can be used with the same level of quality in mobile scenarios. Until the third generation of mobile networks, the need to ensure reliable handovers was still an important issue. On the eve of a new generation of access networks (4G) and increased connectivity between networks of different characteristics commonly called hybrid (satellite, ad-hoc, sensors, wired, WIMAX, LAN, etc.), it is necessary to transfer mechanisms of mobility to future generations of networks. In order to achieve this, it is essential to carry out a comprehensive evaluation of the performance of current protocols and the diverse topologies to suit the new mobility conditions.

\title{
How to reference
}

In order to correctly reference this scholarly work, feel free to copy and paste the following:

H. Hariyanto, R. Wulansari, Adit Kurniawan and Hendrawan (2012). Femtocell Performance Over Non-SLA xDSL Access Network, Mobile Networks, Dr. Jesús Ortiz (Ed.), ISBN: 978-953-51-0593-0, InTech, Available from: http://www.intechopen.com/books/mobile-networks/femtocell-performance-over-non-sla-xdsl-accessnetwork

\section{INTECH}

open science | open minds

\section{InTech Europe}

University Campus STeP Ri

Slavka Krautzeka 83/A

51000 Rijeka, Croatia

Phone: +385 (51) 770447

Fax: +385 (51) 686166

www.intechopen.com

\section{InTech China}

Unit 405, Office Block, Hotel Equatorial Shanghai

No.65, Yan An Road (West), Shanghai, 200040, China

中国上海市延安西路65号上海国际贵都大饭店办公楼 405 单元

Phone: +86-21-62489820

Fax: $+86-21-62489821$ 
(C) 2012 The Author(s). Licensee IntechOpen. This is an open access article distributed under the terms of the Creative Commons Attribution 3.0 License, which permits unrestricted use, distribution, and reproduction in any medium, provided the original work is properly cited. 